\title{
Scale Up Production Indonesian Liquid Propolis From Raw Propolis and Wild Beehive Using Bubbling Vacuum Evaporator
}

\author{
Muhamad Sahlan ${ }^{1,2^{*}}$, Andhika Akhmariadi ${ }^{1}$, Diah Kartika Pratami $^{3}$, Heri Hermansyah ${ }^{1}$, and \\ Anondho Wijanarko ${ }^{1}$ \\ ${ }^{1}$ Department of Chemical Engineering, Faculty of Engineering, Universitas Indonesia, Depok, 16425, \\ West java, Indonesia \\ ${ }^{2}$ Research Center of Biomedical Engineering, Faculty of Engineering, Universitas Indonesia, Depok, \\ 16425, West java, Indonesia \\ ${ }^{3}$ Department of Pharmacognosy and Phytochemistry, Faculty of Pharmacy, Pancasila University. South \\ Jakarta, 12640, DKI Jakarta, Indonesia
}

\begin{abstract}
The process of production propolis on a laboratory scale using a rotary evaporator with capacity one liter of ethanol extract propolis include propylene glycol as solvent medium. Ethanol is evaporated at a temperature of $65^{\circ} \mathrm{C}$ and reduced water content at $80^{\circ} \mathrm{C}$. For the quantity of products can be increased by increasing the capacity of the ethanol extract of propolis and the medium while solvent evaporation to 12 liters and modify the rotary system with a bubbling system (bubbling vacuum evaporator). Then the solvent medium used was replaced with glycerol. The result of $8.02 \mathrm{~kg}$ of raw propolis produced 10.85 liters with the average of total flavonoid content $914.8 \mathrm{mg} / \mathrm{l}$, while for $8 \mathrm{~kg}$ of raw material forest beehive produced 7.65 liters with the average of total flavonoid content $307.2 \mathrm{mg} / \mathrm{l}$. With the capacity production average reaches one liter per day. The resulting product by organoleptically sweet taste, no smell and distinctive of saliva and the color of the product are brown.
\end{abstract}

\section{Introduction}

Products derived from bees include honey, pollen, royal jelly, propolis, and beeswax. One of the bee products that have high economic value and health benefits are high for propolis. Propolis or bee glue, a substance produced by bees and serve to patch up and sterilize the hive [1]. The content of bioactive propolis different in each region depends on the location where the bees live [2,3]. Contained bioactive flavonoids in propolis dominated, with levels nearly $50 \%$. Flavonoids are organic compounds that function as an antibacterial and anticancer, ferulic acid serves as an antibiotic while functioning as an antiviral terpenoid [46].

From the results of field surveys in the fact that propolis is obtained for the majority of these imports on the market, while Indonesia has the potential of propolis that is not less

*Corresponding author: sahlan@che.ui,ac.id 
great. Among beekeepers were still a few who take advantage of using propolis trap [7- 8]. Propolis obtained by extraction of raw propolis, or beehives, which are used for the extraction solvent is ethanol solution; the result is called the extraction of ethanol extract of propolis (EEP) [9]. Propolis wax contained in the ethanol extract of propolis are separated by the addition of water $[10,11]$. After that extract plus solvent medium for the vacuum distillation process is then performed using a vacuum evaporator bubbling to separate the alcohol and reduce the amount of water in the extract. Separation process in the production of propolis ethanol solvent Indonesia using a rotary evaporator before the capacity of one liter with propylene glycol solvent media. Production capacity by using the tool to only one liter per week and similar products such as propolis produced in the market (propylene glycol base). In the present study was carried out modifications to the tool rotary evaporator, by enlarging the capacity of the extract and replace the rotary system to bubble system. Besides the solvent media used is changed from the propylene glycol to glycerol. Thus propolis produced sweet and odorless typical saliva.

\section{Material and Methods}

\subsection{Material}

Raw propolis obtained from bee farms in Jakarta, while the honeycomb obtained from the Sumatran jungle. Auxiliary raw materials such as $96 \%$ ethanol, glycerol, and distilled water obtained from the supplier of industrial chemicals.

\subsection{Propolis Extraction}

The propolis extraction from beehive using Sahlan et al. methods [12]. A total of two kilograms of raw materials are weighed, then crushed materials first become a much smaller size. Ethanol plus $96 \%$ as much as 10 liters and stirred using an overhead stirrer at $150 \mathrm{rpm}$ for eight hours. Extract and then allowed to stand overnight, then filtered using a Buchner funnel which has been coated filter paper (pore diameter, ten $\mu \mathrm{m}$ ), performed with the aid of vacuum filtration of the water jet pump. The filtrate is called ethanol extract propolis (EEP) $96 \%$, while the cake is called resin.

\subsection{Separation Wax Propolis}

The EEP $96 \%$ diluted by the addition of distilled water until the concentration of ethanol to $70 \%$, so that propolis wax deposits formed in a solution of $70 \%$ EEP. Before precipitate filtered propolis wax, wax deposition solution of propolis extract and advance in aging at 50 - $\mathrm{C}$ for 30 minutes using a water bath, and then be continued stored in a freezer at a temperature of $-4{ }^{\circ} \mathrm{C}$ for overnight. After precipitating of propolis wax filtered with a Buchner funnel. The filtrate $\mathrm{pH}\left(\mathrm{EEP} 70 \%\right.$ ) was raised to 6.4 by the addition of $5 \% \mathrm{Na}_{2} \mathrm{CO}_{3}$.

\subsection{Distillation Solvent using Bubbling Vacuum Evaporator}

EEP as much as 10 liters of $70 \%$ plus two liters of glycerol into the bubbling Vacuum Evaporator, is distilled at a temperature of $65^{\circ} \mathrm{C}$ until ethanol stops dripping on the bottom of the condenser, then the temperature was increased to $80^{\circ} \mathrm{C}$ until the product becomes viscous. 


\section{Result and Discussion}

\subsection{Propolis extraction}

Propolis raw material extraction is done by maceration method, which is one method for the extraction of ingredients that can not stand the heat, that is by soaking the material with a specific solvent and in a certain period. Solvents used are ethanol $96 \%$ to extract more robust use of dense concentration. The resin produced from raw material forest honeycomb can be processed into beeswax by heating above $100^{\circ} \mathrm{C}$ until the wax melted and filtered to remove impurities. A resin derived from the raw propolis cannot be recycled as resin from beehives forest, but it is very likely to be other processed as Scrubb $[13,14]$.

\subsection{Separation wax propolis}

After the filtration process, a solution of EEP combined with distilled water until the concentration of ethanol to $70 \%$. The purpose of this dilution is to separate the wax propolis contained in raw materials. From the results of scanning the degree of separation of wax propolis, the optimal concentration for the separation of wax propolis ethanol concentration was $70 \%$ [10]. When added to water extract solution became turbid due to precipitate formed propolis wax. EEP solution then aging at $50{ }^{\circ} \mathrm{C}$ for 30 minutes, then continued to be stored in the freezer overnight to achieve complete separation of wax. Propolis wax precipitate which was originally floated and separated into fused after the process. A solution of ethanol extract of propolis that has been free of wax propolis increased the $\mathrm{pH}$ to 6.4 by addition of $\mathrm{Na}_{2} \mathrm{CO}_{3} 5 \%$ of its original $\mathrm{pH}$ of about 5 . Indonesia $\mathrm{pH}$ of water in an average of about 6.4 below $\mathrm{pH} 7$, to obtain a high solubility in water then the $\mathrm{pH}$ should be adjusted. Media solvent used is glycerol so that the organoleptic taste sweeter products, such as the brown color of the original extract of propolis and odorless saliva [12].

\subsection{Distillation solvent}

Distillation process takes 24 hours, at this stage of the separation of the ethanol extract and a reduction in the amount of water added. In the first stage, the temperature is set at $65^{\circ} \mathrm{C}$, to separate the ethanol found in EEP, so the bioactive propolis ethanol moves to the glycerol. Ethanol separation process carried out for 16 hours or until ethanol stops dripping from the bottom of the condenser. Recycle the ethanol concentration reached only $77 \%$, to be used for extraction is necessary to re-distillation until the concentration reaches $96 \%$. The second stage the temperature was increased to $80{ }^{\circ} \mathrm{C}$, the objective is to reduce water content in the product. The process of reduction of water content takes up to 8 hours.

\subsection{Bubbling vacuum evaporator}

Bubbling Vacuum Evaporator is distillation equipment used for the separation of ethanol from the extract and a reduction in moisture content is the result of modification of the rotary evaporator and a capacity of 12 liters of solution, which consists of 10 liters of EEP solution and 2 liters of solvent media. Where previously the process of separation of ethanol and reduction of water content using a rotary evaporator done. Ethanol is successful in the recycle less than half of the EEP solution that goes into the tool, as well as a longer distillation time. The production capacity of the rotary evaporator was only one liter per week. Scheme of bubbling vacuum evaporator presented in Figure 1. 


\subsection{Total flavonoid content (TFC) of propolis from raw propolis}

Flavonoids are one of the parameters determining the quality because almost half of the bioactive compounds contained in propolis are flavonoid $[6,12,15]$. TFC of propolis cattle averaged about $939 \mathrm{mg} / 1$ in a solution of $70 \%$ EEP and $914 \mathrm{mg} / 1$ in the product. From the data, the trend can be concluded that many TFC is successfully extracted, reflected in a solution of $70 \%$ EEP. So if we want to increase the levels of TFC in the product, we can reduce the ratio of glycerol solvent media, only a consequence of the amount of product produced less.

The TFC in EEP of $96 \%$ and $70 \%$ EEP decreased dramatically up to a fifth, due to propolis wax in a solution of $96 \%$ EEP flavonoids participate as a measurable, while the TFC in the EEP $70 \%$ and the product tends to be stable. Departing from previous experience, to obtain greater flavonoid content in the product, then the ratio should be reduced glycerol solvent media. In the batch 3 and batch 4 of propolis Riau forest amount of solvent glycerol media reduced by half, the result is total flavonoid content in the product increased to twofold $[16,17]$.

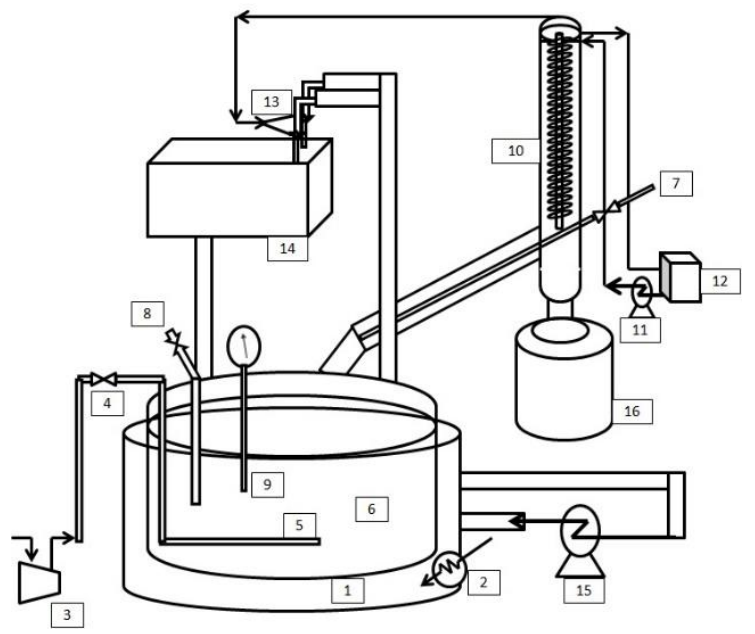

Equipment:

(1) Water Bath,

(2) Thermocouple,

(3) Compressor,

(4) Valve Bubbling,

(5) Bubbler,

(6) Distillation Vessel,

(7) Inlet Extract,

(8) Outlet Product,

(9) Thermometer,

(10) Coil Condensor,

(11) Condensor Pump,

(12) Cooler Sirculation,

(13) Water Jet,

(14) Water Jet Sirculation,

(15) Water Jet Pump,

(16) Distillation Vessel.

Fig. 1. Bubbling Vacum Evaporator Scheme.

\subsection{Mass balance of ethanol}

Ethanol mass balance results can be seen in Figure 2 below :

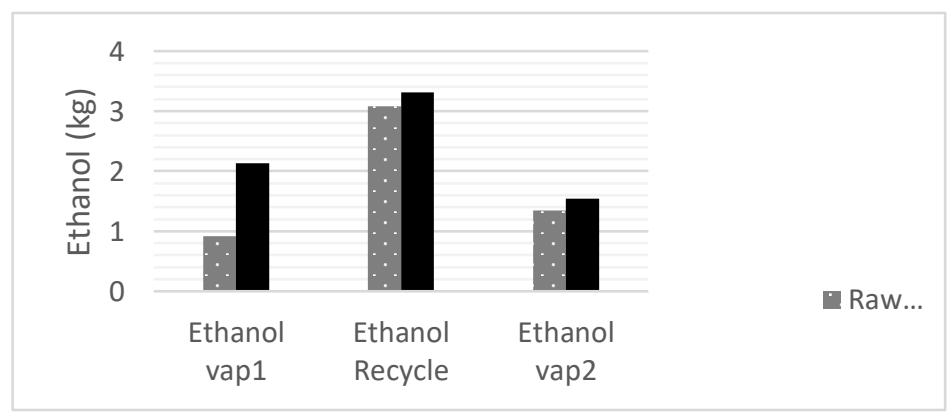

Fig. 2. Mass Balance of Ethanol from Raw Propolis and wild beehive 
Mass balance calculations only focus on components that are considered important, such as flavonoids, ethanol, and water. From mass balance calculations when ethanol is added at the beginning of the process shrink by more than $50 \%$ during the process. This loss occurs during the process of ethanol extraction for 8 hours, the filtration process, the process of aging at $50{ }^{\circ} \mathrm{C}$ for 30 minutes until the distillation process, there is a small portion of ethanol is sucked into the water jet system. So that the fore in order the production process more effective and efficient again is still needed a lot of development. As an example, the process of extraction in order ethanol not too much who evaporate preferably inside it reactor.

\section{Conclusion}

Production propolis Indonesia from $8.02 \mathrm{~kg}$ propolis raw propolis can obtain 10.85 liters and total flavonoid content of an average of $914.8 \mathrm{mg} / 1$ and $8.04 \mathrm{~kg}$ for propolis from wild bee hives in the woods as much as 7.65 liters total flavonoid content of an average of $307.2 \mathrm{mg} /$ 1. Ethanol is lost during the process of achieving an average $50 \%$ of ethanol were added to the process. The production process a batch of propolis Indonesia as a whole process takes 24 hours or three working days with the volume of products reach more than three liters when averaged over a production capacity of one liter per day.

This work is supported by Grant of Indexed International Publication of Student Final Project (Publikasi International Terindeks Untuk Tugas Akhir Mahasiswa / PITTA) 2018 funded by DRPM Universitas Indonesia (No. 2486/UN2.R3.1/HKP.05.00/2018).

\section{References}

1. M. Simone-Finstrom, R. S. Borba, M. Wilson, and M. Spivak, Insects 8, 2 (2017)

2. M. Simone-Finstrom and M. Spivak, Apidologie 41, 3 (2010)

3. V. Bankova, S. De Castro, and M. Marcucci, Apidologie 31, 1 (2000)

4. B. Trusheva, M. Popova, E. B. Koendhori, I. Tsvetkova, C. Naydenski, and V. Bankova, Nat. Prod. Res 25, 6 (2011)

5. W. Syamsudin, Simajuntak, P, Heffen,WL. Am. J. Biochem. Biotechnol 5, 4 (2009)

6. Syamsudin, ASIAN J. Chem 22, 1 (2010)

7. J. M. Sforcin and V. Bankova, J. Ethnopharmacol. 133, 2 (2011)

8. Mahani, B. Nurhadi, E. Subroto, and M. Herudiyanto, in Proceeding University Malaysia Terengganu Annual Sciences (2011)

9. D. K. Pratami, A. Mun, A. Sundowo, and M. Sahlan, Pharmacogn. J. 10, 1 (2018)

10. M. Sahlan and T. Supardi, Int. J. Pharma Bio Sci. 4, 1 (2013)

11. M. Sahlan, D. Dienayati, D. Hamdi, S. Zahra, H. Hermansyah, and M. Chulasiri, Makara J. Technol., 21, 1 (2017)

12. D. Christina et al., in AIP Conference Proceedings 1933, (2018)

13. M. Sahlan and E. Rohmatin, Int. J. Pharm. Pharm. Sci., 9, 5 (2017)

14. A. G. Mahadewi et al., AIP Conf. Proc., 1933, 20005, Feb (2018)

15. M. Funakoshi-Tago et al., Int. Immunopharmacol., (2015)

16. V. Bankova, J. Ethnopharmacol., 100, 1-2 (2005)

17. C.-C. Chang, M.-H. Yang, and H.-M. Wen, J. Food Drug Anal., 10, 3 (2002) 